This paper is a draft of chapter 12 of The Blackwell Companion to Mutual Funds, tentatively scheduled for publication in October 2009. The final version will include revisions. The book is edited by John A. Haslem, and includes contributions by William Bernstein, John C. Bogle, Conrad Cciccotello, Garry L. Gastineau, John A. Haslem, Paul D. Kaplan \& Don Phillips, Burton Malkiel, David M. Smith and Larry E. Swedroe.

\title{
PERFORMANCE OF ACTIVELY MANAGED VERSUS INDEX FUNDS: THE VANGUARD CASE
}

\section{EDWARD TOWER}

Paul Merriman: "How does Vanguard justify with this great family of index funds also having all of these actively managed funds?" [Merriman (2006)]

John C. Bogle: “Well I don't run Vanguard any longer, but I will take plenty of responsibility for having those active funds in all of the years I ran it. And the answer to that is really a couple of things. One, a lot of investors, no matter how persuasive the case for indexing is, and it's overpoweringly persuasive, just don't quite get it. They want a little more activity. They want something to watch. Index funds, as you all know, are roughly as exciting as watching paint dry or maybe watching the grass grow. They create great returns but they're not that exciting. So what we tried to do and what I tried to do personally was pick good managers, and that's very, very hard to do. I want to be clear on that, and I have some hits and some runs and some errors in that category, have funds with multiple managers, so you get a much broader diversification, which is not unlike an index fund. . . . [for example, take] our Windsor II fund. It's a large cap value fund. And it has five different managers. I think that's the number now. And so you are going to tend to have a value average return for that fund. And then, actually, make sure you have the other two big advantages of indexing, or three really, no sales commissions, very low expense ratios, because I negotiated with all those advisors and got those fees as low as I could possibly get them, and hire advisors with low portfolio turnover. An article was done by some professors at Duke University about a year ago and they showed that our active managers in the life of the index fund actually did a hair better than the index fund. [Reinker and Tower (2005)]. On the other hand if we had started the comparison a little bit later, the active managers would have done a little bit worse. But I think it's a valid strategy. What can I do and tell you? I'm still $80 \%$ indexed." [Bogle (2006)].

As if by reply, Dan Wiener, editor of the FFSA Independent Guide to the

Vanguard Funds, writes:

"Vanguard wants you to 'believe' in indexing. Your faith in indexing is the cornerstone of their business. But it's a lie. And your trust could cost you... plenty!. ... Indexing doesn't work for you. It works for them. The big famous Index funds at 
Vanguard have chronically underperformed over the last few years, exposing conservative investors to the worst risks of bear markets. But Vanguard knows investors who plunk money into an index become "passive." Their money goes "dead." And Vanguard never has to worry about these clients getting antsy. Indexing is a great business_but it's a lousy investment!" [Wiener (2007).]

\section{Introduction}

Is Bogle (2006) correct that Vanguard's index and managed equity funds are comparable, and should investors follow his example and hold a mix of both? Is Wiener correct that Vanguard's index funds, especially the big index funds, underperform? How should Vanguard investors choose between Vanguard's index funds and its managed funds?

This study asks:

- Did Vanguard's managed funds outperform their indexed counterparts?

- Were the managers of Vanguard's active funds wise stock pickers and style pickers?

- Did the degree of outperformance of a managed mutual fund predict the degree of future outperformance?

- Has the degree of outperformance of Vanguard's managed funds been rising, falling or staying the same?

- Which predicted outperformance best: past outperformance, the number of Morningstar stars awarded to funds for past performance, or Wiener's (2003) sell, hold or buy recommendations?

- What was the best combination of these predictors?

Methodology 
This chapter defines the tracking index fund basket (for short the tracking index) of a managed fund as that collection of indexed funds whose monthly returns most closely track the returns of the managed fund. Each Vanguard managed fund can be matched to a tracking basket of Vanguard index funds that produces the same return plus a differential. If the average differential, alpha, is positive the return of the managed fund is superior to that of the tracking index. This chapter uses the geometric alpha. This is the amount by which the geometric average return of a mutual fund exceeds the geometric average return of its tracking index. The geometric alpha is more useful than the standard arithmetic alpha, for it measures how much the mutual fund out-returns its tracking index over the period analyzed, rather than the average annual excess return, measured by the arithmetic alpha. Two funds that have the same tracking index and total return over a time period, but different standard deviations of return will have different arithmetic alphas, but the same geometric alphas.

Wiener (2006, p.186) provides correlations of returns between different Vanguard equity funds to help investors reduce risk. Morningstar's (2009) portfolio instant X-Ray is also useful. It describes the composition of each managed fund as a combination of the nine style groups (from large cap value, through mid cap blend, and small cap growth), and it distinguishes between domestic and foreign equity.

A complementary tool is the one provided here, the tracking index. Investors who find that one of their managed funds substantially duplicates one of their 
index funds may wish to lighten their holdings of one or the other in order to maintain portfolio diversification.

The chapter ignores taxes. Thus, the analysis applies to mutual funds in a tax sheltered account. Taxes are ignored, because mutual funds are less appealing as a saving vehicle in a taxable account, as there, one can hold individual stocks, selling off losers for capital losses when need be and postponing taxable sales or else passing them onto heirs tax free. The variability of individual stock returns facilitates tax loss harvesting in a non tax-sheltered account.

The first step is to describe each of Vanguard's managed funds in terms of its index funds. The index funds used are the 12 diversified equity funds available over the ten-year period, July 1, 1998-June 31, 2008. These along with their symbols are

1. VFINX 500 Index

2. VEIEX Emerging Market Stock Index

3. VEURX European Stock Index

4. VEXMX Extended Market Index

5. VIGRX Growth Index

6. VIMSX Mid-Cap Index

7. VPACX Pacific Stock Index

8. NAESX Small-Cap Index

9. VISGX Small-Cap Growth Index

10. VISVX Small-Cap Value Index

11. VTSMX Total Stock Market Index, and

12. VIVAX Value Index

The inception date of the Large-Cap Index, VLACX, is January 2004. It is used as part of the tracking index for funds born after that date.

Each index fund represents an investment in a patch of the stock market, i.e. a particular style of investment. This list has gaps in coverage. There are no 
Vanguard indexes that correspond to international growth, international value or international small. The Vanguard index funds for Mid-Cap Growth and Mid-Cap Value have inception dates of 2006 , too late for inclusion in this study. If such funds had existed for the entire period, it would have been possible to find tracking indexes that were closer trackers of the managed funds.

Three of the index funds were established only in May 1998. The need to use as many index funds as possible for as many years as possible restricted the study to the ten-year period, July 1998 through June 2008.

Here is the list of the Vanguard managed funds that have operated for this whole ten-year period and met our criteria (discussed below) for inclusion in the study:
1. VHCOX Capital Opportunity
2. VDIGX Dividend Growth (formerly Utilities Income)
3. VEIPX Equity Income
4. VEXPX Explorer
5. VXGEX Global Equity
6. VQNPX Growth and Income
7. VGEQX Growth Equity
8. VINEX International Explorer
9. VWIGX International Growth
10. VTRIX International Value
11. VMGRX Mid-Cap Growth
12. VMRGX Morgan Growth
13. VCMPX PRIMECAP
14. VASVX Selected Value
15. VSEQX Strategic Equity
16. VWUSX U.S. Growth
17. VWNDX Windsor
18. VWNFX Windsor II

The study also considers several recent additions listed below with the first full month of observations for returns from Morningstar (2008): 
1. VFTSX 06/2000

2. VUVLX $07 / 2000$

3. VCLVX $01 / 2002$

4. VDEQX $07 / 2005$

5. VSLVX 01/2006

6. VSGPX 02/2006

7. VDAIX

8. VSTCX

9. VSLIX

10. VSBMX
FTSE Social Index investor class

U.S. Value

Capital Value

Diversified Equity

Structured Large-Cap Value Institutional Plus

Structured Large-Cap Growth Institutional Plus

Dividend Appreciation

Strategic Small-Cap Equity

Structured Large-Cap Equity Institutional

Structured Broad Market Institutional

There are 18 managed funds that have existed for the whole period (the old funds) and ten additional funds that have existed for shorter periods (the young funds). These are Vanguard's diversified funds whose median proportion of assets invested in cash and bonds was less than $9 \%$ at the annual reporting times indicated on Morningstar Principia (2008). The young funds consist of seven managed funds, an index fund that uses social screening criteria (FTSE Soc), a fund of funds (Diversified Equity), that is permitted to vary its mix of funds, and Dividend Appreciation, which as chapter 12 discusses is an enhanced index fund.

The structured funds, all of which are in the young collection, are institutional or institutional plus funds, and they do not have other share class counterparts. These are share classes like the investor or Admiral share classes and are not limited to institutions. They simply have the "institutional" share class name. They have high minimum investment levels ( $\$ 5$ million and $\$ 200$ million respectively). While not many investors will be able to invest in them, it is worthwhile to see whether they beat the index funds, and whether less wealthy investors should lobby to have them made available, perhaps with higher fees attached for smaller accounts. 
No funds, managed or indexed, were closed down during the period, so there is no survivorship bias.

The Investor share class carries higher expenses than the Admiral share class. But some funds do not have Admiral shares, so to keep the sample size large and for the sake of uniformity the study works with Investor shares.

Investors are concerned with real returns, so we adjust nominal returns by the consumer price index provided in Morningstar (2008) to get real returns. Henceforth, "return" unless accompanied by "nominal," indicates real return. The formula used for the conversion is

(1) $1+R=[1+N] /[1+I]$,

where $\mathrm{R}$ is the real rate of return, $\mathrm{N}$ is the nominal rate of return, and $\mathrm{I}$ is the rate of inflation in the consumer price index, with all expressed as a proportion per month.

To describe the return of a managed fund (say PRIMECAP) in terms of the index fund returns, the monthly return of PRIMECAP is regressed on the monthly returns of all of the indexes, while constraining all of the coefficients of the index funds to be non-negative and to sum to one. The result is:

(2) $R_{\text {PRIMECAP }}=+4.33 / 12+0.18 R_{S \& P 500}+0.04 R_{\text {European }}+0.41 R_{\text {Growth }}$ $+0.03 R_{\text {Mid-Cap }}+0.16 R_{\text {Small-Cap Growth }}+0.18 R_{\text {Small-Cap }}$ $+0.01 \mathrm{R}$, Total Stock Market

where R denotes monthly (real) return in percentage points per year. Henceforth except where confusion might result, all returns and return differences are simply $\%$ per month or year. This regression says that PRIMECAP is an asset whose return is best described as the return of a basket of index funds consisting of 
18\% invested in the 500 Index fund, 4\% in European Stock Index, $41 \%$ in Growth Index, 3\% in Mid-Cap Index, 16\% in Small-Cap Growth Index, and 1\% in Total Stock Market Index (which due to rounding error adds to $101 \%$ ), with an additional return of $4.33 / 12 \%$ per month, and a random term, where the index basket is rebalanced at the beginning of each month. This index basket is defined as the tracking index. Here the managed fund outperforms the tracking index by $4.33 / 12 \%$ per month or $4.33 \%$ per year, the arithmetic $\alpha$. This composition of the tracking index is recorded in Table 1. This method of style analysis was developed by Sharpe (1992) and is explained there and by Bodie, Kane and Marcus (2008, pp.875-879). Sharpe writes (1992, p.13) “.. . style analysis provides measures that reflect how returns act, rather than a simplistic concept of what the portfolios include." His paper is online, clear, displays helpful graphs and is easy to read.

Insert Table 1 about here.

In the tables and figures, all returns and return differentials are real and are continuously compounded. Continuously compounded returns are easy to work with because the average return over a number of periods is just the average single period return: a security that returns continuously compounded geometric rates of return of $2 \%$ in one year and $4 \%$ in the following year returns a continuously compounded geometric rate of return of $3 \%$ over the two-year period.

The solver feature of Microsoft Excel is used to perform all of the calculations, as in Tower and Yang (2008). Next the regression coefficients are 
used to calculate the tracking index and its return over the period. The geometric alpha is calculated as the geometric average annual return of the managed fund minus that of the index basket, where both are continuously compounded. For PRIMECAP, the geometric alpha is $4.03 \%$ per year. It is smaller than the arithmetic alpha of $4.33 \%$ per year (the constant in the regression), and it is recorded in Table 2.

Insert Table 2 about here.

The use of the tracking basket is an attempt to deal with Kizer's (2005) point that in assessing managed funds versus index funds one must compare managed performance with index performance of comparable style.

Returns are not risk adjusted. Instead, the tables simply report the standard deviations of monthly returns of the fund and the tracking index. Given alpha, the risk-averse investor will prefer the fund with the lower standard deviation.

One could follow Reinker and Tower (2004) and calculate a risk-adjusted alpha by combining a low risk asset (such as an inflation protected security) with the security (the managed fund or the tracking basket) that has the higher standard deviation of return, until the standard deviation of return for the combined portfolio fell to that of the lower standard-deviation-of-return security. The return of the combination minus that of the lower standard-deviation-of return security is the risk-adjusted return differential. But the result depends on the lowrisk asset chosen. Moreover, the analysis may be misleading. Suppose fund $A$ returns more each period than does fund $B$, but fund $B$ has a lower standard 
deviation of return. Then risk adjusting fund $\mathrm{A}$ (using a low return, low risk asset) may bring its return below that of fund $B$, yet no investor would choose fund $B$ over fund A. It is easy to see that this paradox occurs if B is almost riskless and the low-risk asset has a low return.

\section{In Defense of Geometric Alpha}

Let $R_{1}$ and $R_{2}$ be successive monthly returns, expressed as proportions. The average arithmetic return is $\left(R_{1}+R_{2}\right) / 2$, the average return each period. The average geometric return is $\left.\left(1+R_{1}\right)^{*}\left(1+R_{2}\right)\right]^{5}-1$, the common return each period that would generate the observed return over the entire time span.

The expected one-period return exceeds the expected long-period return if future returns are drawn evenly from past returns without replacement. For example, if the past annual returns were $0 \%$ and $300 \%$, the expected one year return is the average of $0 \%$ and $300 \%=150 \%$. This is the past arithmetic rate of return. This is also the expected annual return over any number of years if we expect that the return in all future periods will be drawn randomly from past returns with replacement. To see this, recognize that in that case, after two years we expect to have returned sequences of $0 \%$ then $300 \%, 0 \%$ then $0 \%, 300 \%$ then $0 \%$ and $300 \%$ then $300 \%$ each with probabilities of $0.25 \%$. After two years one dollar becomes an expected $\$ 6.25=(2.5)^{2}$, for an expected annual return of $150 \%$. However, the expected annual return over a two year span, when returns are drawn evenly from past returns is $[(1+0)(1+3)]^{5}-1=100 \%$. This is the past geometric rate of return. It is also the expected return over many periods when future returns are drawn evenly without replacement from past returns. The 
reason it is lower than the expected return when expected returns are calculated from past returns with replacement is that in the replacement case, the biggest returns are occasionally married with the biggest returns, so the magic of compounding raises the expected return beyond the geometric average return. To some extent equity prices are characterized by regression to the mean, i.e. big returns are likely to be married with small returns in the future. If this is the case, the sensible policy is to report only geometric average returns and use them to calculate geometric alpha, and we follow it here. But the standard procedure in the literature is to use the arithmetic alpha. Kritzman (2002, chapter 4) addresses this issue and the discussion here is based on his discussion.

The arithmetic average return exceeds the geometric average return by more, the higher the standard deviation of return, so using arithmetic alphas instead of geometric averages as the performance criterion makes a fund that is more risky relative to its tracking index look more appealing relative to a fund that is less risky relative to its tracking index.

\section{The Tracking Indexes for the Old Funds}

Table 1 presents the tracking indexes for each of the 20 old funds. Windsor and Windsor II mimic a combination of lots of the Value Index Fund and a little of the Small-Cap Value Index Fund. The Growth and Income Fund mostly tracks the S\&P500 Index Fund. Reassuringly, the international managed funds have tracking baskets consisting mostly of the international index funds. The returns of all of the index funds have been quite similar over the ten-year period. Their ten-year real geometric average returns ranged from 1.17\% per year to - 
$0.08 \%$ per year, with an average of $0.34 \%$. All of them performed less well than the three Vanguard bond funds discussed at the bottom of the table.

Using only the S\&P500 index as a benchmark for managed funds is a misguided strategy. Tables 1 and 4 (for the old and young funds, respectively) show that all tracking baskets require at least two different index funds, and no single index fund (neither the S\&P500 Index Fund nor any other) is consistently used across all managed funds. However, one index fund: Total Stock Market Index Fund, adds little explanatory power.

Most of the results from the linear regression are not surprising. For example the Growth Equity Fund invests heavily in equities highly correlated with the Growth Index Fund. However, some striking patterns arise, illuminating the management style of funds. For example, Table 1 shows that Windsor has historically invested $86 \%$ of its funds in equities linked to the Value Index Fund although Morningstar (2008) lists it as a large blend fund. Similarly, the Mid-Cap Growth Fund held $81 \%$ of its assets in securities linked to the Extended Market Index Fund, while Morningstar describes it as a midcap growth stock, and the Growth Equity Fund is described by Morningstar (2008) as a large value fund, while it held $56 \%$ of its portfolio In assets linked to the Extended Market Index Fund. The Dividend Growth Fund is described in Morningstar (2008) as large blend, but $77 \%$ of its securities were linked over the period to the value index. Table 1 clearly shows that caveat emptor is necessary in a world of style drift and misleading fund labels.

\section{Prowess of Style Jumping and Equity Choice for the Old Funds}


Table 2 records some important results from the analysis. The $R^{2}$ measures the closeness of fit of the managed fund to its tracking index. It is the correlation squared of the monthly continuously compounded geometric real returns of the managed fund with its tracking index. The prowess of style jumping and equity choice over the entire period (abbreviated PSE) is alpha. A positive alpha may reflect wise stock picking within a style class, or it may reflect wise style jumping, moving into styles just before they appreciate. It does not reflect the wisdom of the average style choice, for that is controlled for by the selection of the index basket.

The average return differential is a positive $0.30 \%$ per year. On average the managed funds were $5 \%$ riskier than the tracking indexes, with the ratio of the managed standard deviation of monthly return to that of the tracking basket being 1.05. Hence, managed funds are more risky.

This is surprising in view of the fact that managed funds tend to be less fully invested in equity than the index funds. Perhaps managed funds tend to be more risky, because they are less diversified. Referring back to the quote from John Bogle (2006), Windsor II, which strives to improve diversification by hiring more managers, is one of the few funds that have a lower risk than its tracking basket, and it has the third lowest risk relative to its tracking basket of any managed fund in the collection. This is diversification by spreading mismanagement risk.

Table 2 shows that, over the entire period, nine funds have a negative alpha and nine have a positive alpha. Capital Opportunity and PRIMECAP are the only 
two with a t statistic for alpha, $\mathrm{t}_{\alpha}$, greater than 2 , and U.S. Growth is the only one with a $t_{\alpha}$ more negative than -2 . These alphas are significantly different from zero at better than the $5 \%$ level.

Breaking up the period into two equal halves generates further insights. $\alpha_{w 1}$ and $\alpha_{W_{2}}$ are the alphas calculated for the first and second five year halves, with the performance of the whole 10-year period tracking index as the benchmark. These alphas reflect the ability of the managed funds to beat the index basket that reflects average style choice over the whole ten-year period. Since they reflect prowess in both style jumping and equity choice in the two half periods, they are denoted by PSE1 and PSE2, respectively.

$\alpha_{H 1}$ and $\alpha_{H 2}$ are the alphas calculated for the first and second five-year halves of the period, with the performance of the corresponding half-period tracking index as the benchmark. These alphas reflect the ability of the managed funds to beat the index basket that reflects the average style choice over the half period. The alphas with the half-period tracking benchmarks reflect the prowess of equity choice, because style jumping from the first half of the period to the second, if any, is reflected in the change in the index basket. Hence we label them prowess of equity choice, PE1 and PE2. Both the PE's and PSE's indicate management prowess net of any additional cost imposed by the higher expenses of managed funds and the additional costs associated with the excess turnover of managed funds. In the first half both average PSE1 and average PE1 are positive and in the second half they are both negative. Thus there is positive prowess of combined style jumping and equity choice in the first half and 
negative prowess in the second. The same is true of the prowess of equity choice: positive in the first half and negative in the second half. The use of only two sub periods is arbitrary and this approach does not reflect style jumping within sub periods. That would emerge in the calculations as stock selection prowess.

The average of PSE1 and PSE2 is +0.30 , the same as PSE, meaning that over the whole-period the prowess of style jumping and equity choice swamps transaction costs and expenses. The average of the PEs is $+0.125 \%$ per year, implying that equity selection prowess swamps costs and expenses.

Dividing the whole period in two for calculating the short-period tracking benchmarks is arbitrary. It could be divided into as many as ten parts, one for each year. If managers are consistently wise style jumpers, finer divisions should generate higher values for the PSEs and lower values for the PEs.

Table 2 includes the Dan Wiener's sell (-1), hold (0) and buy (1) ratings and the number of Morningstar (2003) stars for each managed fund, both for July 2003 (the middle of the entire period). Their predictive power is examined in a later section.

\section{Prescient Style Jumping?}

If managers are successful style jumpers the half-period tracking indexes will perform better than the whole period one. So if managers are wise style jumpers, the average alpha calculated for the half-period tracking indexes will be lower than the average alpha calculated for the whole-period tracking index. PS is the prowess of style jumping over the entire period. We measure it by the 
average of the whole alphas ( $\alpha_{w_{1}}$ and $\left.\alpha_{w_{2}}\right)$ minus the average of the half alphas $\left(\alpha_{H 1}\right.$ and $\left.\alpha_{H 2}\right)$ We find that PS is positive. Prescient style jumping has yielded a positive return of $0.175 \%$ per year. This prowess figure is the difference between two average alphas, both of which reflect the additional expenses and transaction costs of managed funds. Consequently, these additional expenses and transaction costs cancel out in taking the difference, so PS does not reflect them.

Thus, on average fund managers made prescient style choices. Individuals may wish to adjust their styles in accordance with anticipated differential returns to different styles if they are able to correctly predict differential style returns. A wide range of style predictions used to be provided on the GMO web site (2009), which were evaluated in The Economist (2008) and by Tower (2008), but the range of styles that GMO attempts to predict was narrowed in December 2008.

\section{Alpha Fell}

Barras, Scaillet and Wermers (2008) argue that conventional analysis finds that more managers are able to outperform the market than is truly the case, because these studies do not correct for luck. They aggregate different share classes of the same mutual fund by assets under management. By correcting for luck, they discover that the number of managers that beat the market net of expenses has dramatically fallen over time, so virtually none existed by 2006: $0.6 \%$ of fund managers, although on a gross return basis $9.6 \%$ of mutual fund managers display market-beating ability. They (p.1) 
... find a significant proportion of skilled (positive alpha) funds prior to 1995, but almost none by 2006, accompanied by a large increase in unskilled (negative alpha) fund managers due to both a large reduction in the proportion of fund managers with stockpicking skills and to a persistent level of expenses that exceed the value generated by these managers.

Does the BSW regularity that alpha is falling hold for Vanguard's managed funds?

\section{Insert Table 3 about here.}

The first columns of Table 3 provide the $t$ values for the alphas of Table 2. The $R^{2} s$ are indicated for the two half-periods, for the alphas that use the wholeperiod tracking index as benchmark.

Each year's alpha (with the long tracking index as the benchmark) for each mutual fund was regressed on time, measured in years. The coefficients on time are indicated as the Annual PSEG. The average rate of growth of alpha, PSEG, is $-0.28 \%$ per year. Thus alpha declined by over a quarter of a percent per year.

Subsequent columns compare first and second half figures. The average jump from the first half to the second in prowess of style and equity selection is -1.08 percentage points per year. The average jump from the first half to the second in prowess of equity selection is -1.51 percentage points per year. The average style jumping prowess rose from -.03 percentage points per year in the first half to 0.38 percentage points in the second half, for an increase from the first half to the second of 0.42 percentage point. Thus the prowess of style jumping improved, but the improvement is not enough to offset the decline in the 
prowess of equity choice, so total management prowess declined between the two halves.

How much of the differential performance was accounted for by cash drag? On average, mutual funds held $4 \%$ of their portfolios as cash during the whole period. Using the 500 Index Fund to get the equity benchmark real return (-0.4 percentage points per year) and Vanguard's short term treasury fund to get the money market return (+3.92 percentage points per year), the cash boost was $4 \%^{*}(+0.0040+0.0392)=0.17$ percentage points per year during the first five years as managers got out of negative real return stocks into positive real return short term bonds. In the second half, the cash drag was 0.02 percentage points per year as managers got out of positive real return stocks into negative real return short term bonds. Thus we would have expected managers to return 0.19 percentage points per year less in the second half. In fact the reduction is 1.08 percentage points, so cash drag explains only $18 \%$ of the reduction in alpha.

\section{Insert Figures 1 and 2 about here.}

Figure 1 shows how the average annual alpha (whole) has fallen. Figure 2 shows the same thing for the median average annual alpha (whole). The largest outliers are for the period July 1999-June 2001. From July 1999 through June 2000 , the managed funds outperformed their index baskets by an average of over 7 percentage points; From July 2000 through June 2001, the median outperformance is over $2.5 \%$. A puzzle is why managed funds performed so well in this period where the tech bubble topped out. Were it not for that one period managed funds would have underperformed on average in both halves of the 
period. A small part of the answer may be market timing. The average Vanguard managed fund's holding of cash was $5.1 \%$ at the end of $1999,5.2 \%$ at the end of 2000 and an average of $3.8 \%$ on average from 2002 to 2006 .

The old managed funds on average have expense ratios and turnover that are greater than the index funds. The average expense ratios and average turnover fell for both the old managed and index funds. Tower and Zheng (2008) find that a one hundred percentage point increase in turnover reduces return by 0.83 percentage points per year. Using this calculation, the underperformance of managed funds would be expected to fall from 0.66 percentage points per year in the first half of the period to 0.54 percentage points per year in the second half of the period for an increase in alpha of 0.12 points per year. Thus the increasing disadvantage of managed funds swims against the tide of a reduced disadvantage on the basis of differential expense ratios and turnover.

\section{How have the young funds performed?}

\section{Insert Table 4 about here.}

Table 4 shows the tracking index and performance of each of Vanguard's young funds. On average they underperformed their corresponding index baskets by 1.90 percentage points per year. Their risk was one percent higher. Of particular interest is Vanguard's FTSE social index fund. It underperformed its tracking index by 2.98 percentage points per year and was $12 \%$ riskier. The two institutional funds, Structured Large Cap Equity I and Structured Broad Market I, underperformed their index baskets by an average of 0.68 percentage points per year and the two institutional plus funds, Structured Large Value IP and 
Structured Large growth IP, underperformed by an average of $4.22 \%$ per year. So investors who are unable to commit the $\$ 5$ million minimum investment for the former or the $\$ 200$ million minimum investment for the latter should not feel deprived. One shouldn't put much faith in these numbers for the young funds, because the inception of half of them is after the start of 2006. Still, averaging the underperformance of these 8 young funds over the whole period with the average outperformance of the 18 old funds over the entire period, the managed funds now outperform by $(0.42 * 18-1.90 * 11) / 29 \%=-0.46 \%$ per year. So by this criterion managed funds underperformed their tracking indexes.

The Total Stock Market Index fund plays no role in any of the tracking indexes shown in Tables 1 and 4, except for a 1\% role for Capital Opportunity. Why? My conjecture is that fund managers rebalance frequently, which means that the components of that index show up in the tracking indexes, but not the Total Stock Market Index itself.

\section{Did $\mathbf{R}^{2}$ Predict Performance (Including Young Funds)?}

\section{Insert Figure 3 about here.}

Some funds have tracking indexes that closely track them. Some funds do not. The latter are funds that do not have indexes that capture performance well. For example, Dividend Growth has an $\mathrm{R}^{2}$ of only $59 \%$. All of the other $\mathrm{R}^{2}$ 's are at least $73 \%$. Is there any relationship between the closeness of fit of the tracking index and outperformance? We see from Figure 3's graph of alpha versus $\mathrm{R}^{2}$ that 8 out of 9 of the managed funds that most closely track their tracking index underperformed their tracking index, while 11 out of the 19 managed funds that 
more loosely track their tracking indexes outperformed their tracking index. The relationship is a weak one, especially because of the weak performance of the Dividend Growth Fund.

The regression line crosses the $\mathrm{R}^{2}$ axis at $82 \%$. Thus, investors would have been well advised to buy index funds instead of managed funds that closely tracked them. However, managed funds whose performance is not well explained by a tracking index are more likely to beat the tracking index. Why? Perhaps only competent managers dare to deviate from the indexes. Perhaps risk-averse executives at Vanguard are willing to give fund managers their heads to deviate from the indexes only when they have lots of confidence in the fund managers or the fund uses a style not captured by Vanguard's index funds, and this confidence turns out to be well placed. It could be argued that when we compare low- $R^{2}$ funds to their tracking indexes we are making an apples-tooranges comparison and should disregard these results, because there is no good tracking index, but a more compelling argument is that it is still worthwhile to discover whether the markets colonized by such managed funds beat the closest available index basket.

\section{Is the Past Prologue? Did Past Performance Predict Future Performance?}

Insert Figures 4 and 5 about here.

It would make no sense to examine alphas for managed funds if alphas have no predictive power. To explore this we look at Figure 4. This figure shows that there is a positive relationship between $\alpha_{w}$ in the first half and $\alpha_{w}$ in the second half. Each 1 percentage point increase in $\alpha_{w 1}$ predicts a 0.23 percentage 
point increase in $\alpha_{W 2}$. The relationship is similar for the alternative way of calculating $\alpha$ depicted in Figure 5. Here $\alpha_{\mathrm{H}_{1}}$ predicts $\alpha_{\mathrm{H} 2}$, with each 1 percentage point increase in $\alpha_{1}$ predicting a $0.26 \%$ increase in $\alpha_{2}$. The $R^{2} s$ are reasonably high $41 \%$ and $26 \%$ respectively. Thus the $\alpha$ 's did predict.

Is this view supported by regressions using annual data? The time series and cross section data for the old funds are pooled to explain each fund's annual alpha as a function of the previous year's annual alpha:

$$
\begin{gathered}
\alpha_{\text {AW, }}=+0.252 \alpha_{\text {AW, } t-1}+0.232, \\
(t=3.41, P=0.08 \%)
\end{gathered}
$$

where $R^{2}=6.8 \%$, adjusted $R^{2}=6.2 \%$, observations $=162, F$ is significant at the $0.08 \%$ probability level, and $\mathrm{P}$ is the significance level on a two tailed test.

Several regressions were also run on the same data with longer lags. One useful one is

$$
\begin{aligned}
\alpha_{A W, t}=+0.018 \alpha_{A W, t-1}+0.080 \alpha_{A W, t-2}+0.086 \alpha_{A W, t-3} \\
+0.099 \alpha_{A W, t-4}-0.054,
\end{aligned}
$$

where $R^{2}=10.7 \%$, adjusted $R^{2}=7.2 \%$, observations $=108$, and $F$ is significant at the $2 \%$ probability level. In equation 4 , the coefficients of past alphas sum to 0.282 .

Thus the figures and the regressions support the idea that alpha is predictable. The size and significance of the degree of predictability in equations (3) are high enough to make one wonder what mechanisms are at work.

Did a Combination of $\mathrm{R}^{2}$ and Past Alpha Predict Performance? 
Since $\mathrm{R}^{2}$ and alpha independently predict performance it is natural to ask whether the two combined predict performance. The answer is:

(5) $\alpha_{A W, t}=$

$$
-0.107 R^{2}+0.173 \alpha A W t-1+8.03
$$

$$
(\mathrm{t}=-1.5, \mathrm{P}=0.15) \quad(\mathrm{t}=1.2, \mathrm{P}=0.24)
$$

where $R^{2}=21.4 \%$, adjusted $R^{2}=10.9 \%$, observations $=108$, and $F$ is significant at the $16 \%$ probability level.

Thus, both variables predict in the direction anticipated and have some predictive power.

This predictability might be due to autocorrelation in expense ratios, turnover, the share of assets held out of the stock market, stock picking genius of managers, or persistent returns of the style of the mutual fund, not captured by the styles of the indexes. As examples of the last point, Vanguard has no international value index, international growth index or international mid or small cap index. Bogle (2007, p.xvii) writes "Fund investors are confident that they can easily select superior fund managers. They are wrong." This regression is weak evidence that $R^{2}$ and past alpha predict future alpha.

\section{Did Morningstar Stars Predict?}

\section{Insert Figure 6 about here.}

Morningstar rates the past performance of mutual funds relative to other funds in the same style category, by granting them between one and five stars. Is there any relationship between the Morningstar stars and the alphas? Figure 6 shows the regression of $\alpha_{W 2}$ (July 2003-June 2008) on the number of Morningstar stars as published in Morningstar (2003) and based on performance through 
June 2003. Each Morningstar star is found to be worth 0.70 percentage points per year of excess return. The $\mathrm{R}^{2}$ is $14 \%$. Thus the Morningstar stars in this case did predict the alphas.

\section{Did Dan Wiener's Ratings Predict?}

Insert Figure 7 about here.

Each month Dan Wiener publishes an edition of The Independent Adviser for Vanguard Investors. In it he rates Vanguard mutual funds as sell, hold or buy. What is the relationship between his recommendations and the alphas? Figure 7 explores this. On the horizontal axis is Wiener's July (2003) recommendation, constructed at the midpoint of our data. A sell is represented as -1 , a hold is represented as 0 , and a buy is represented as +1 . On the vertical axis is $\alpha_{w 2}$. The graph shows that each unit increase in Wiener's recommendation represents a 1.63 percentage points increase in $\alpha_{w_{2}}$, the second half five year performance. The $\mathrm{R}^{2}$ is $44 \%$. Variations on both the Morningstar and Wiener regressions were carried out with the stars or ratings associated with the tracking index added.

The added variables were expected to have negative signs, because if the index funds were top performers the managed funds they mimic would be more likely to have negative alphas. But in both cases they had the unexpected (positive) sign.

On the basis of $R^{2} s$, Wiener beat the Morningstar stars or past alphas in predicting performance of the Vanguard managed funds.

\section{The Best Prediction Equation}


To find the best predictor a series of regressions to predict $\alpha_{w 2}$. The predictions used were $\alpha_{w 1}$, the number of Morningstar (2003) "stars" for the mutual fund, the number of Morningstar stars for the tracking index, Wiener's rating for the mutual fund, and Wiener's rating for the tracking index. The expected the sign pattern is $(+,+,-,+,-)$. Variables with coefficients that had the "wrong" signs were successively eliminated. Those with the t's that had the highest absolute values were eliminated first.

This process of distillation generated

(6) $\alpha_{W 2}=1.06$ DW Rating + $(t=1.91, P=7.6 \%)$
$0.133 \alpha_{W 1} \quad-0.82$ $(\mathrm{t}=1.63, \mathrm{P}=12 \%)$

where $R^{2}=52 \%$, adjusted $R^{2}=46 \%$, observations $=18$, and $F$ is significant at the $0.4 \%$ probability level.

Thus, even in combination with the number of Morningstar (2003) stars and past performance, Dan Wiener's (2003) recommendation is still the most powerful predictor. We have considered only one observation period and one prediction period, so these qualitative results might not be repeated. The relationship between the prediction and the predictor is shown in Figure 8. Insert Figure 8 about here.

\section{Is Wiener Right That Vanguard's Managed Funds are Better Than its Index Funds?}

Wiener (2007), in the quote at the beginning of this paper, denigrates the idea of investing in broad-based index funds. If Wiener is right that the big, famous index funds at Vanguard are particularly poor choices for investors, the managed funds that have big weights for the 500 index fund should outperform it. 
Lumping all the managed funds (old and young alike) together and excluding the FTSE social index, we find that the managed funds underperform the tracking basket on average by $0.44 \%$ per year. For the funds that have at least a $58 \%$ weight on the 500 index fund, the underperformance is $1.99 \%$ per year. Thus, funds that track the S\&P500 closely, considerably under performed their tracking indexes, making Wiener's assertion suspect. Dan Wiener has written to me that this test is an unfair characterization of his recommendations. He writes that one must evaluate managed funds on a case-by-case basis. For example, his newsletter has consistently recommended against holding Growth Equity.

But Wiener's quote begs investigation of the question whether some patches of the equities market are better managed than indexed. Bogle (2002) asks whether managed funds beat the index for various styles. Let's ask the same question, using our model.

For the collection of old funds, alpha is regressed on all of the coefficients that determine the tracking index, while suppressing the constant. Table 5 presents the results. The regression coefficients are labeled the alpha components. Alpha for each managed fund is explained as the sum of the alpha components, each multiplied by the corresponding tracking coefficient from Table 1. A positive alpha component for an index fund means that the parts of managed funds that are mimicked by that index fund outperform it. So for example a managed fund that is mimicked by an equal combination of the Vanguard 500 Index Fund and the Vanguard Small-Cap Index Fund is expected to outperform it by $(-.02+.28) / 2 \%=0.135 \%$ per year. 
Insert Table 5 about here.

None of the coefficients are significantly different from 0 at the ten percent level. And the equation itself is not significant. Thus we find no style where Vanguard managed funds differ from the funds that make up their tracking indexes.

The alpha component for the 500 Index Fund is slightly negative, so contrary to Wiener's conjecture, it outperforms the managed funds based on it. The four small cap indexes (including the Extended Market Index) have three positive and one relatively large negative coefficient, so we can't say that indexing works less well for small caps. Similarly, the international indexes have one positive and two negative signs. The large positive coefficient for the Total Stock Market Index, reflects that it plays no role in any tracking index for any managed fund, except for a tiny role in Capital Opportunity, with its large alpha.

Both Bogle (2007) and Swensen (2005) advocate investing in broadbased indexes. Swensen (2005) refers to optimum indexing as the selection of index funds that are broadly based enough to minimize transaction costs and provide diversification. It is important to remember the proposition that if markets are efficient, investors should hold all equities in proportion to their market capitalization, which is another rationale for broad-based indexing. Bogle (2007, pp. 204-206) suggests owning just a few broad based index funds. Bogle (2009) pithily summarizes: "Owning the market remains the strategy of choice." William Bernstein (2009) believes that a modest excess long-term return can be obtained by making small and infrequent adjustments in asset allocation opposite large 
changes in asset class valuation. From Figures 1 and 2, managed funds have underperformed their indexed counterparts over the last 5 out of 7 years, whether one looks at average return differentials or median return differentials. Thus while July 1998 through June 2001 supports the Wiener quote's denigration of indexing in general, recent history does not bear out his view. Wiener responded (April 2009) to an earlier draft of this paper that his position is "it may be that individual investors can choose active managers presciently."

Wiener's (2007) belief that offering index funds is more profitable than offering managed funds, quoted at the beginning of the paper, recalls an analogous argument employed by Paul Krugman's (1998). Krugman says that when he drives from Boston to New York and faces a headwind he doesn't drive more slowly. He compensates by depressing the accelerator further and maintaining his speed. Likewise, he argues, imports from abroad, do not cause unemployment. This economic headwind signals the Federal Reserve to sop up the incipient unemployment by depressing the interest rate accelerator, which stimulates investment and leaves employment where it was before. Similarly, when investors invest in a low-cost, low-turnover, broad-based Vanguard index fund, Vanguard is able to sop up the incipient profits by depressing the expense ratio it charges. That Vanguard is unusual in doing this is the thrust of many of John Bogle's speeches and much of his writing. Bogle (2003) also advocates laws that require mutual funds to be run in the interest of the investor and regulations that require mutual funds to present management fees and 
transaction costs more transparently, which would assure that investors reap more of the benefits of potential cost savings throughout the industry.

It may be that individual investors can pick styles presciently. If so, that argues for slice and dice indexing combined with managed funds for parts of the market not covered by index funds, rather than exclusive use of managed funds.

\section{Summary}

- Did Vanguard's managed funds outperform their indexed counterparts? Answer: Over the study's ten year period, the average Vanguard managed fund outperformed at first, and subsequently underperformed. Over the entire period the average managed fund outperformed its index basket counterpart, but the median fund underperformed, and when we include the more recently introduced funds, the average active managed fund underperformed.

- Were the managers of Vanguard's active funds wise stock pickers and style jumpers? Answer: Over the last ten years, for closely tracked funds, no; and for loosely tracked funds, with large variability, yes.

- Did the degree of outperformance of a managed mutual fund predict the degree of future outperformance? Answer: Yes to some degree.

- Did the alphas for Vanguard's managed funds rise, fall or stay the same? Answer: Over our ten year period, they have been falling. This reflects substantial out performance during the height of the tech bubble and its deflation between July 1999 and June 2001. I wonder whether this trend continued during the market sell off of late 2008 and early 2009 . 
- Did the sell, hold or buy recommendations of Dan Wiener's (2003) FFSA Independent Guide to the Vanguard Funds predict outperformance? Answer: Yes, and they performed better than past performance or the number of Morningstar stars awarded to funds for past performance.

\section{Conclusion}

The study found that Vanguard's index and managed equity funds are comparable.

There seems to be little reason to build a portfolio solely out of one or the other if one wishes to overweight some style categories, especially since Vanguard's managed equity funds are able to overweight patches of the market not overweighted by its index funds. For example, there are no Vanguard international value, international growth and international small index funds, although Vanguard's new Mid-Cap Growth Index and Mid-Cap Value index funds and its prospective International Small-Cap Index Fund capture three more parts of the market for its index funds.

However, the study does find support for the finding of Barras, Scaillet, and Wermers (2008) that the advantage of managed funds has declined. In the first three years of our ten-year period Vanguard's managed funds on average outperformed their tracking index fund basket. In the subsequent seven-year period they underperformed. Similarly, in the first half most of Vanguard's managed funds outperformed, and in the second half most underperformed. Specifically, the average alpha in the first half was $0.86 \%$ per year and in the 
second half it was $-0.43 \%$ per year. In the first half 27 out of 36 alphas were positive; in the second half 11 out of 36 alphas were positive.

The study was completed at a bad time, because it misses all the volatility of late 2008 and early 2009. It will be fruitful to see whether the regularities found here continue to hold.

\section{References}

Barras, L, O. Scaillet, and R. R. Wermers. 2008: False Discoveries in Mutual Fund Performance: Measuring Luck in Estimated Alphas. College Park, MD: University of Maryland, R. H. Smith Research Paper Series, 06-043.

Bernstein, W. J. 2009: Personal correspondence.

Bodie Z., A. Kane, and A. J. Marcus. 2008: Essentials of Investments. New York: McGraw Hill.

Bogle, J. C. 2002: An Index Fund Fundamentalist, Journal of Portfolio Management 28:3 (Spring), 31-38.

Bogle, J. C. 2003: Statement of John C. Bogle Before the U.S. House of Representatives, Sub-Committee on Capital Markets, Insurance and Government Sponsored Enterprises of the Committee on Financial Services. Washington, DC: GPO (June 18). http://financialservices.house.gov/media/pdf/061803jb.pdf

Bogle, J. C. 2006: Interview with Paul Merriman on "Sound Investing," August 4. http://www.fundadvice.com.

Bogle, J. C. 2007: The Little Book of Common Sense Investing. Hoboken, NJ: John Wiley \& Sons.

Bogle, J. C. 2009: Six lessons for investors. The Wall Street Journal, January 8, A15.

GMO. 2009: https://www.gmo.com.

Kizer, J. 2005: Index Fundamentalism Revisited: Redux, Journal of Portfolio Management 31:2 (Winter),112-119.

Kritzman, M. P. 2002: Puzzles of Finance. Hoboken, NJ: John Wiley \& Sons. 
Krugman, P. 1998: The Accidental Theorist and Other Dispatches from The Dismal Science. New York: W. W. Norton.

Merriman, P. 2006: Interview with John Bogle on "Sound Investing," August 4. http://www.fund-advice.com.

Morningstar. 2003: Morningstar Principia, July (CD).

Morningstar. 2008: Morningstar Principia, July (CD).

Morningstar. 2009: Morninstar Instant XRay.

http://portfolio.morningstar.com/NewPort/Free/InstantXRayDEntry.aspx?dt=0.705 5475.

Reinker, K. S., and E. Tower. 2004: Index Fundamentalism Revisited, Journal of Portfolio Management 13:2 (Summer), 37-50.

Reinker, K. S., and E. Tower. 2005: Are Vanguard's Managers Good StockPickers or Style-Pickers? Journal of Portfolio Management 30:4 (Spring), 109111.

Rodriguez, A. and E. Tower. 2008: Do Vanguard's Managed Funds Beat its Index Funds? Looking for Prescient Stock and Style Selection, Journal of Indexes 11:2 (March/April), 26-35.

Sharpe, W. F. 1992: Asset Allocation: Management Style and Performance Measurement, Journal of Portfolio Management 18:2 (Winter), 7-19.

Swensen, D. 2005: Unconventional Success: A Fundamental Approach to Personal Investment. New York: Simon and Schuster.

The Economist. 2008: Marketview: The Long and Short of It, August 3. http://www.economist.com/finance/displaystory.cfm?story_id=11870287.

Tower, E. 2008: Are GMO's Predictions Prescient? Working paper, Duke University, Department of Economics.

http://www.econ.duke.edu/Papers/PDF/GMO Predictions1.pdf.

Tower, E. and C.-Y. Yang. 2008: DFA Versus Vanguard: Has DFA Outperformed Vanguard by Enough to Justify its Advisor Fees? Journal of Investing 17:4 (Winter), 71-82.

Tower, E. and W. Zheng. 2008: Ranking Mutual Fund Families: Minimum Expenses and Maximum Loads as Markers for Moral Turpitude, International Review of Economics 55:4 (December), 315-350. 
Wiener, D. 2003: The Independent Adviser for Vanguard Investors, July.

Wiener, D. 2006: The 2006 FFSA Independent Guide to the Vanguard Funds. Potomac, MD: Fund Family Shareholder Association.

Wiener, D. 2007: Action Plan for Vanguard Investors: A Publication of The Independent Adviser for Vanguard Investors. Potomac, MD: Fund Family Shareholder Association.

\section{Acknowledgements}

This chapter builds on Rodriguez and Tower (2008). It uses more recent data and more funds, with some modifications to the methodology, tests new hypotheses, and focuses on a longer time period. Thanks go to Paul Holden, Susan Iddings, Ken Reinker, Allan Sleeman, Phil Steinmeyer, and Dan Wiener for help with the paper. Their approval is not implied.

EDWARD TOWER is Professor of Economics at Duke University. tower@econ.duke.edu 


\section{Table 2. Prowess of Style and Equity Choice for the Old Funds.}

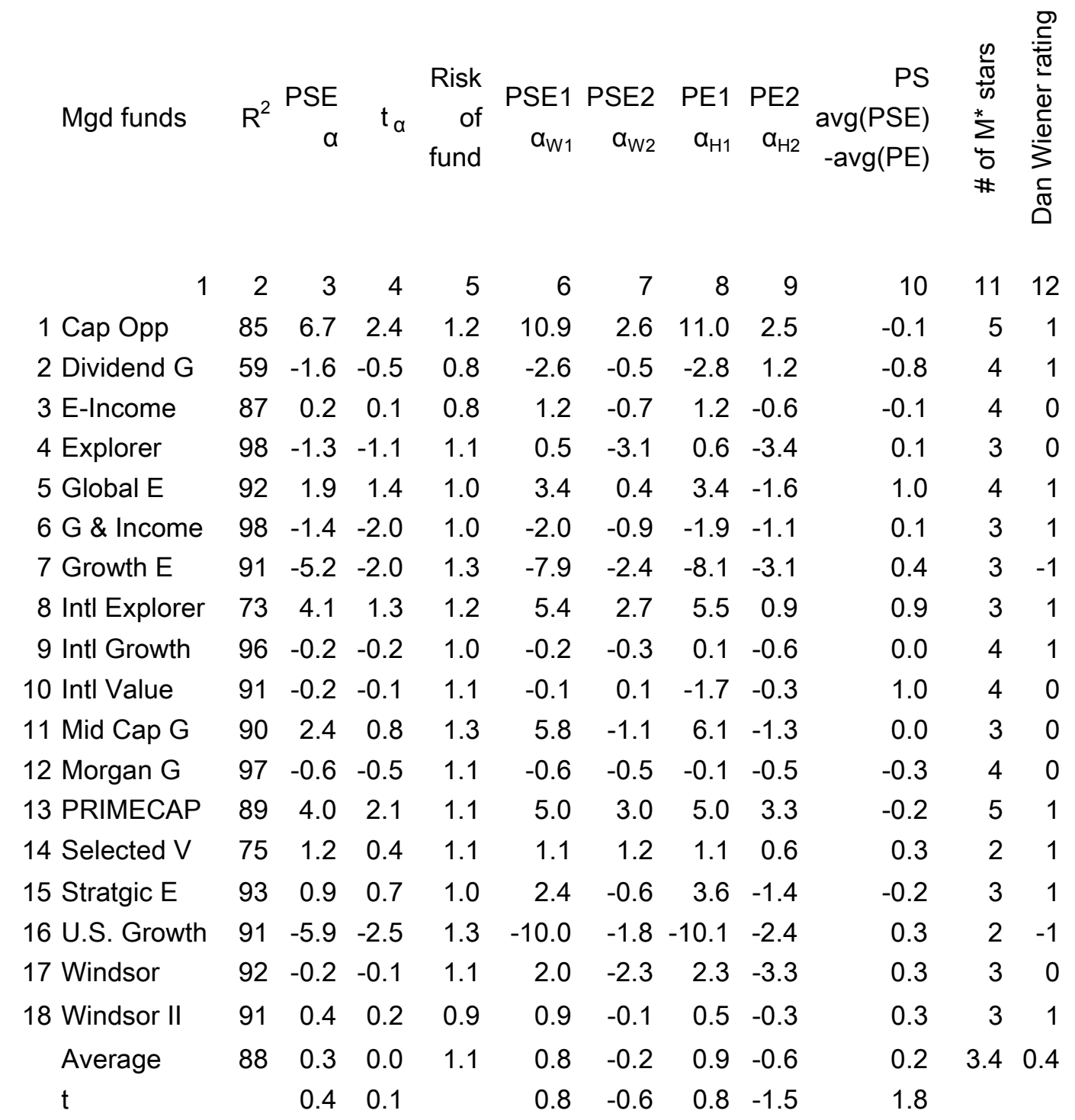

Numbers in columns 2-9 are expressed in \% pts/year.

$R^{2}$ is closeness of fit to tracking index.

PSE is prowess of style and equity choice over whole period. It is measured by $\alpha$.

Risk of fund is measured as the standard deviation of monthly real return for the fund divided by that of the tracking index. Fund beats if less than one

PSEi is prowess of style and equity choice in half $i$, where $i=1$ or 2 , denoting 1 st or 2 nd half of period. It is measured by $a_{\mathrm{Wi}}$, where $\mathrm{W}$ stands for whole and means that the tracking index used for comparison is that for the entire period.

PEi denotes prowess of equity choice for period $i$. It is measured by $\alpha_{H i}$, where $\mathrm{H}$ stands for half and means that the tracking index used for comparison is that of period $i$.

PS denotes prowess of style choice. It is measured by average $\alpha_{W}$ minus average $\alpha_{H}$. 


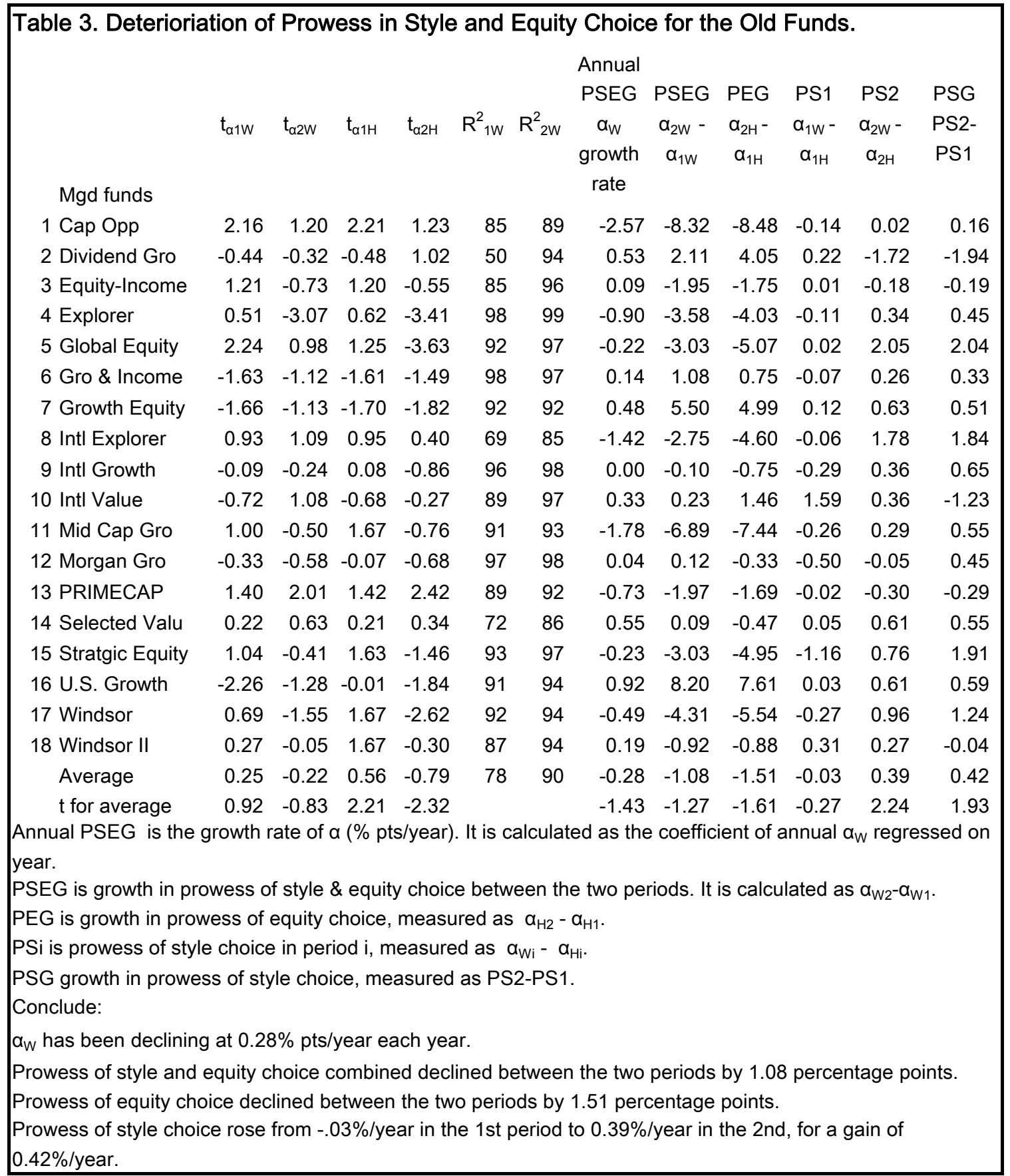




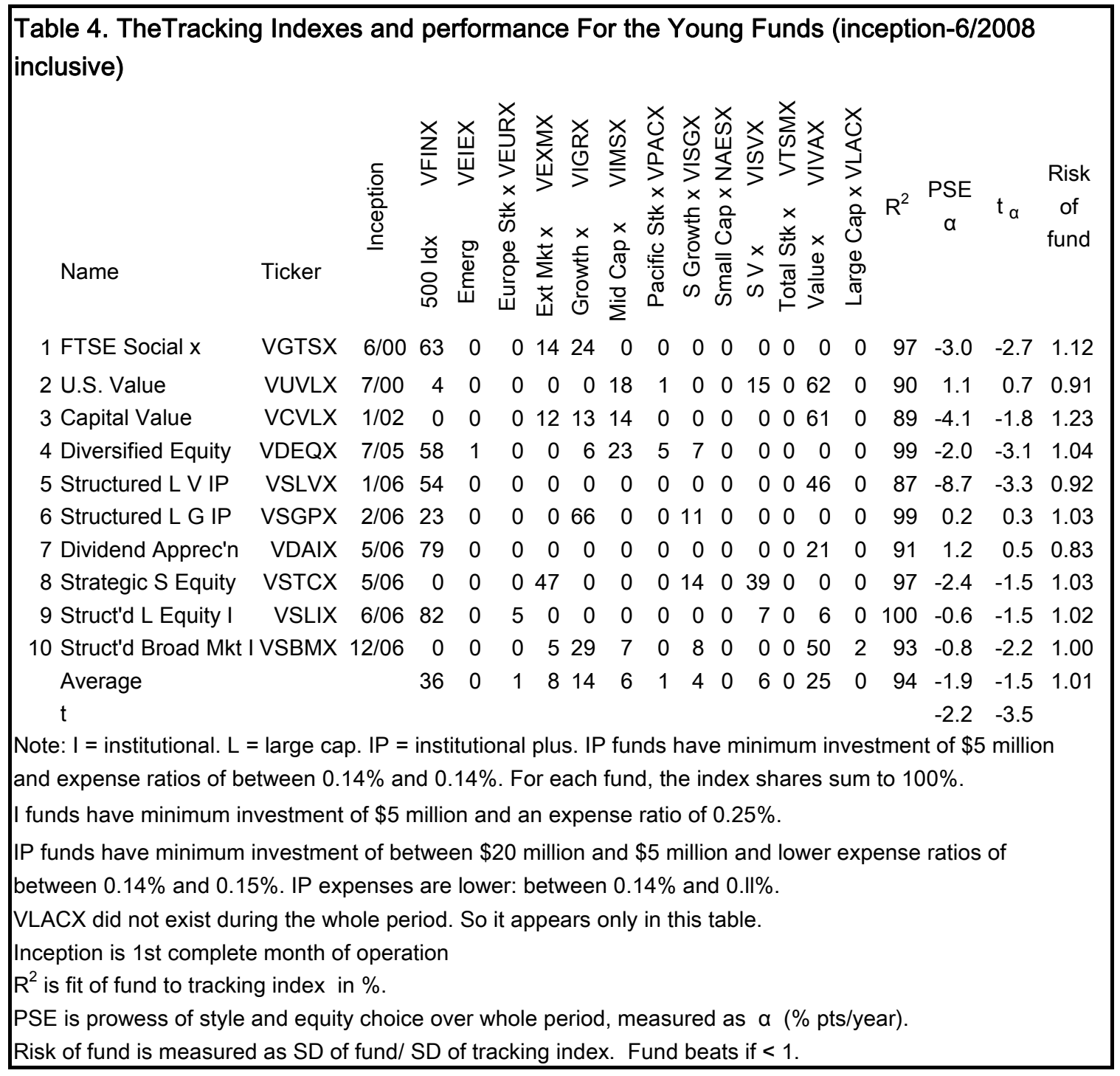




\section{Table 5. Which Index Styles Do Managed Funds Improve Upon?}

$\begin{array}{lrrrr}\text { Index } & \begin{array}{r}\text { Alpha } \\ \text { Components }\end{array} & \begin{array}{r}\text { Standard } \\ \text { Error }\end{array} & \text { t Stat } & \text { P-Value } \\ \text { 500 Index } & -0.02 & 0.04 & -0.35 & 0.73 \\ \text { Em Mkt Idx } & 0.34 & 0.59 & 0.57 & 0.59 \\ \text { Eur Stk Idx } & -0.07 & 0.09 & -0.81 & 0.45 \\ \text { ExtMkt Idx } & 0.07 & 0.06 & 1.04 & 0.34 \\ \text { Gr Idx } & -0.08 & 0.05 & -1.73 & 0.14 \\ \text { Mid Cap Idx } & 0.18 & 0.22 & 0.83 & 0.44 \\ \text { Pac Stk Idx } & -0.04 & 0.28 & -0.15 & 0.89 \\ \text { SmCp Gr Idx } & -0.29 & 0.28 & -1.03 & 0.34 \\ \text { SmCp Idx } & 0.28 & 0.22 & 1.28 & 0.25 \\ \text { SmCp VI Idx } & 0.03 & 0.10 & 0.26 & 0.80 \\ \text { Tot Stk } & 7.58 & 4.93 & 1.54 & 0.17 \\ \text { Val Idx } & 0.00 & 0.02 & -0.15 & 0.89\end{array}$

Observations $=18 . \mathrm{R}$ square $=0.50$. Adjusted $\mathrm{R}$ square $=-0.58$.

$F$ significance $=0.85$. The $\%$ return of the managed fund is the sum of the mimicking shares of Table 1 times the respective coefficients.

The coefficients indicate the amount by which the managed funds do better than the indexes. Thus an index with a negative coefficient outperforms the managed fund which it mimics. , no coefficients are significantly different from zero at the $10 \%$ level. The equation is not significant. So the conclusion is that we have not discovered a style where managed funds differ significantly from index funds. 


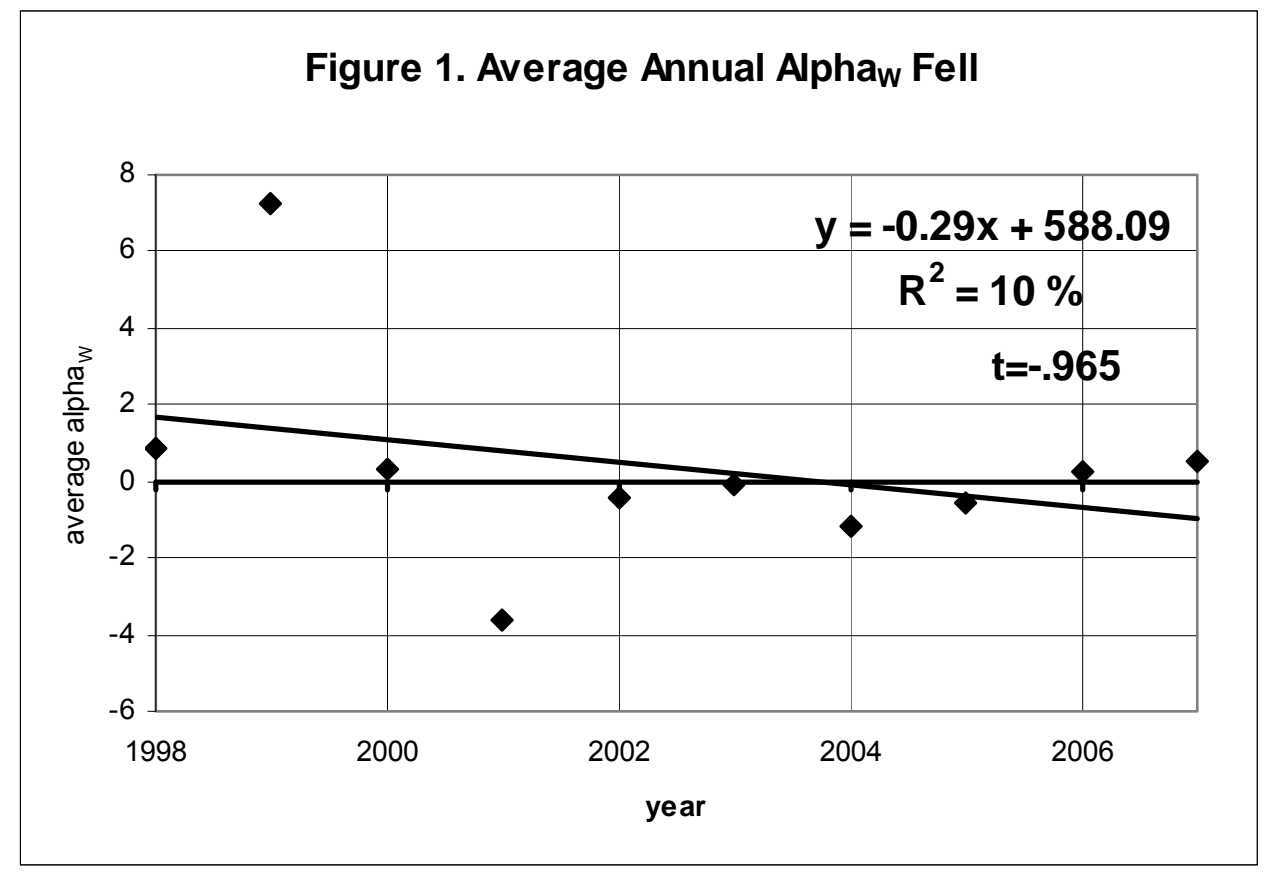




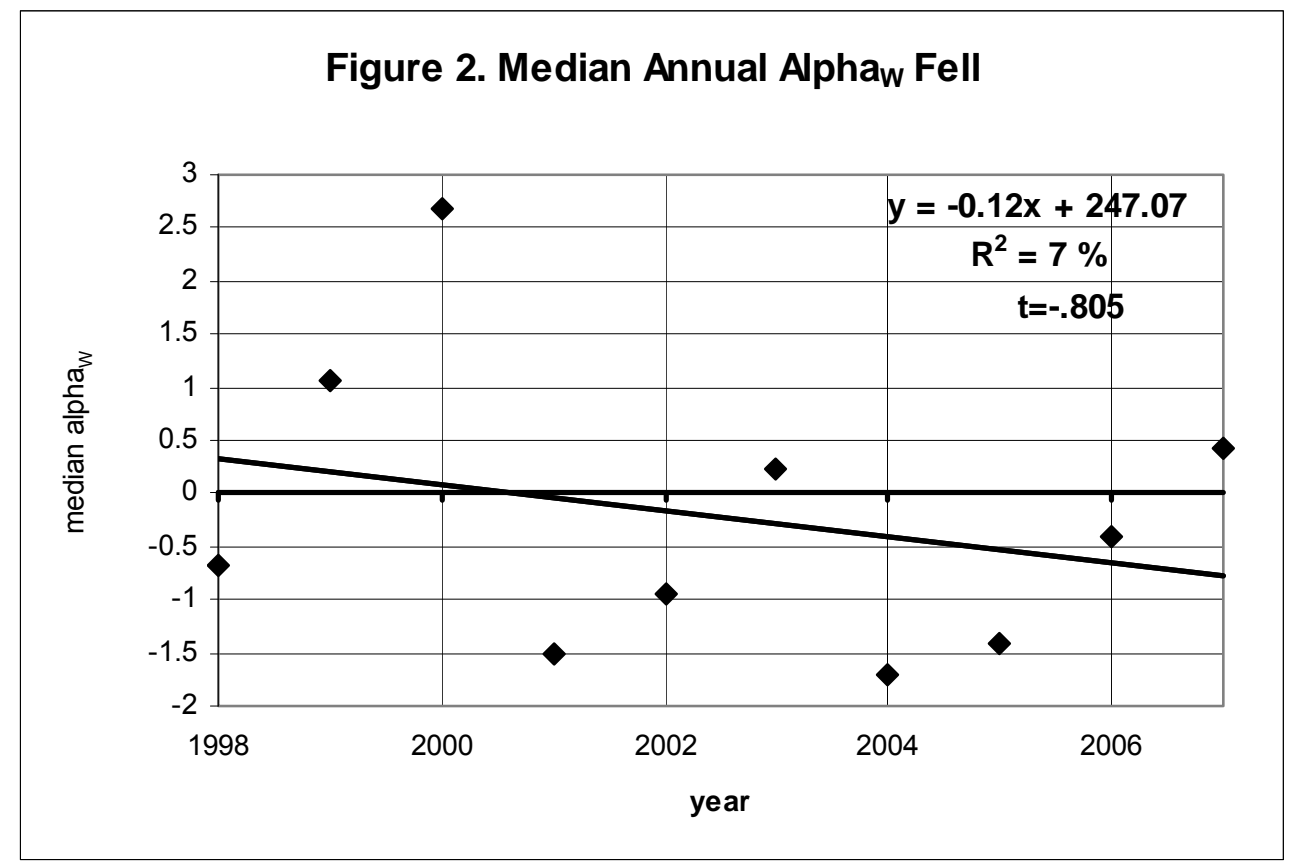




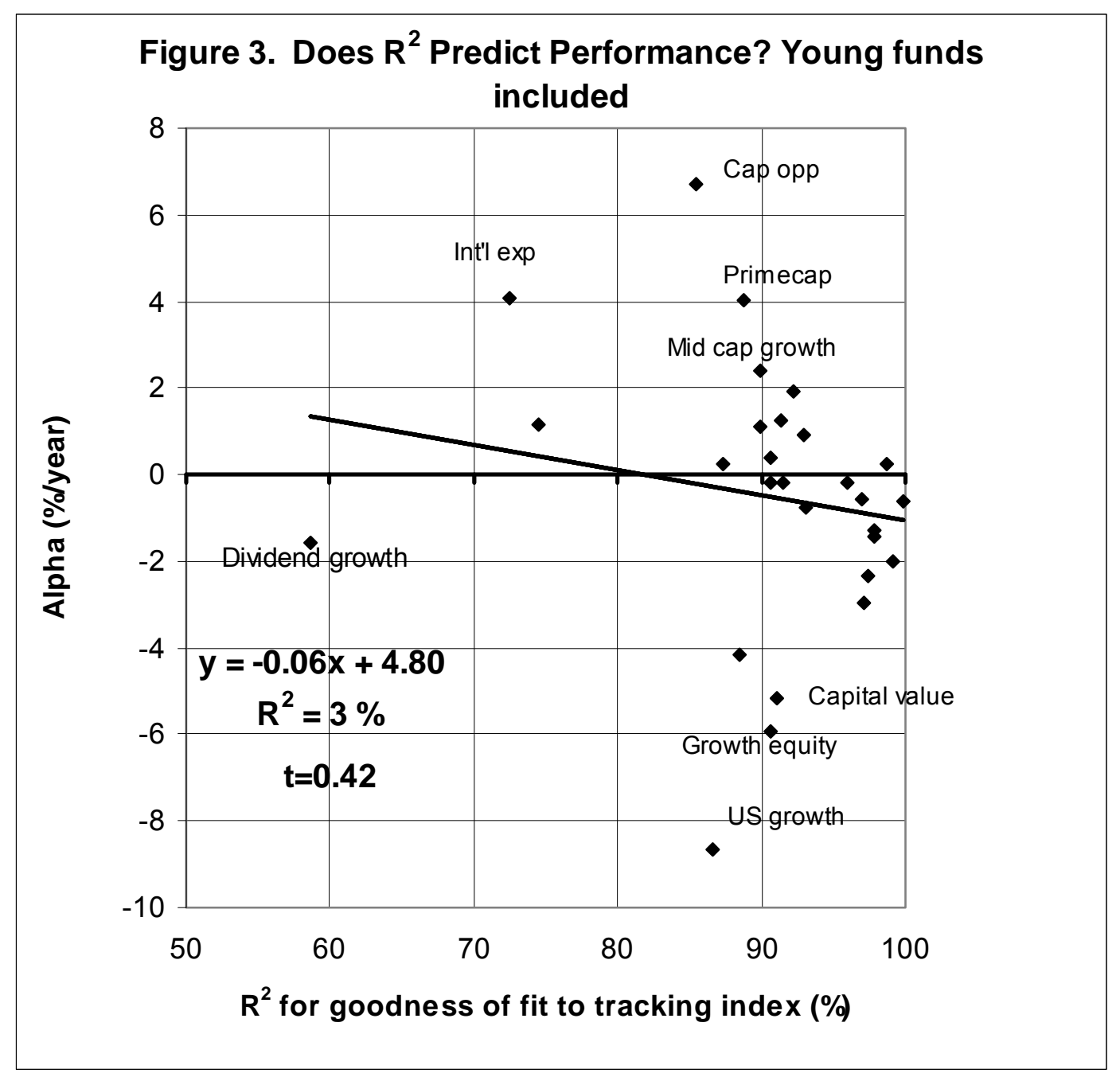




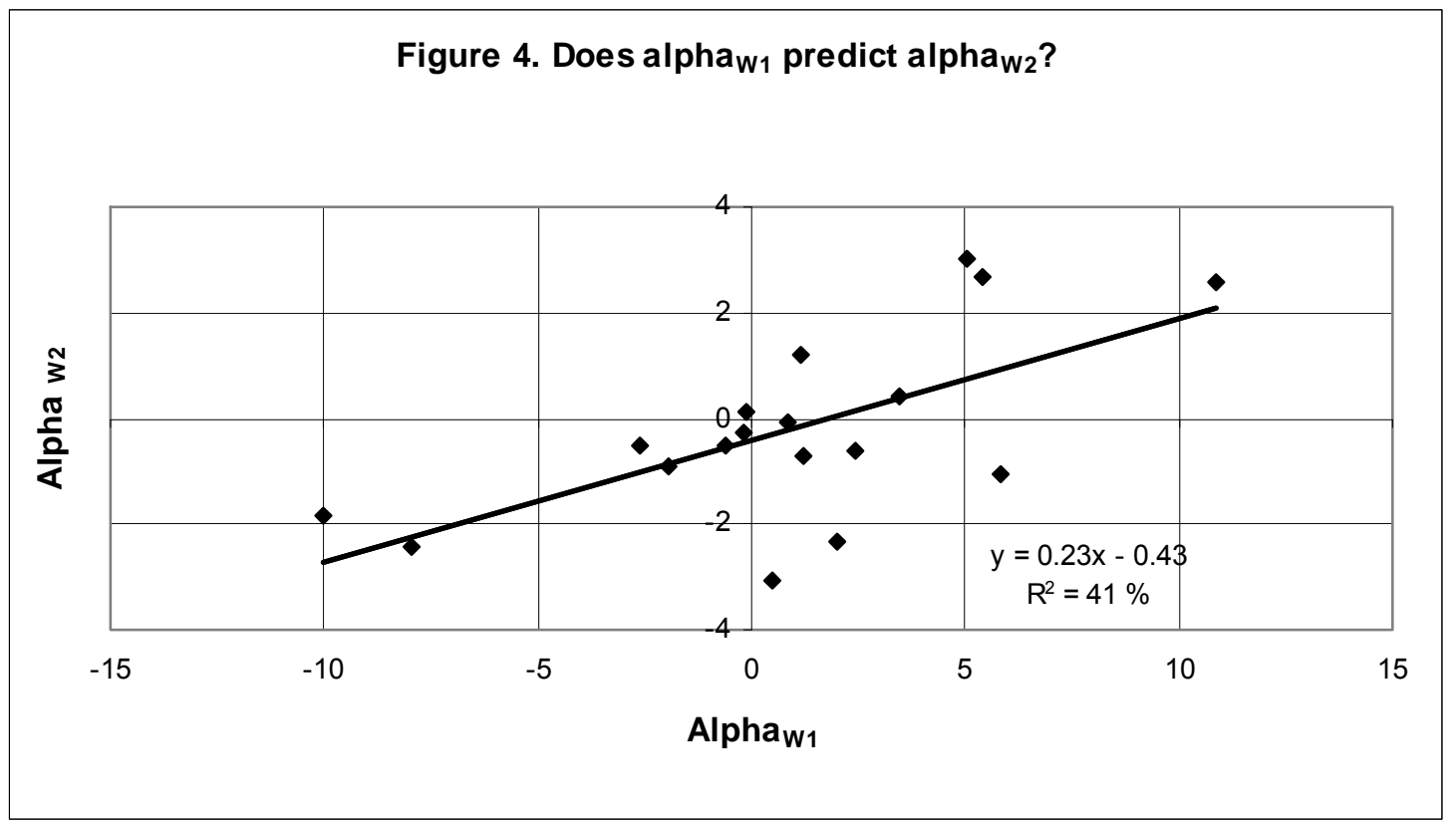




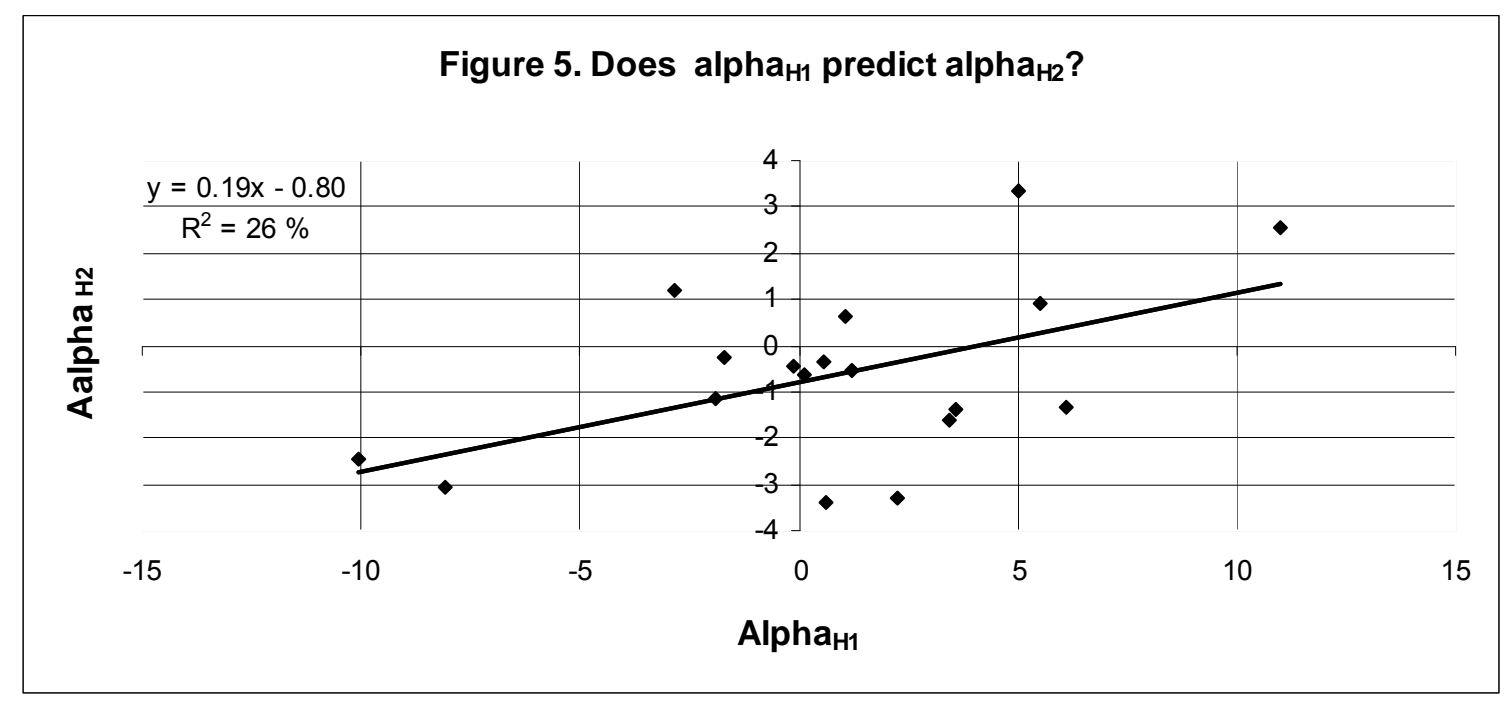




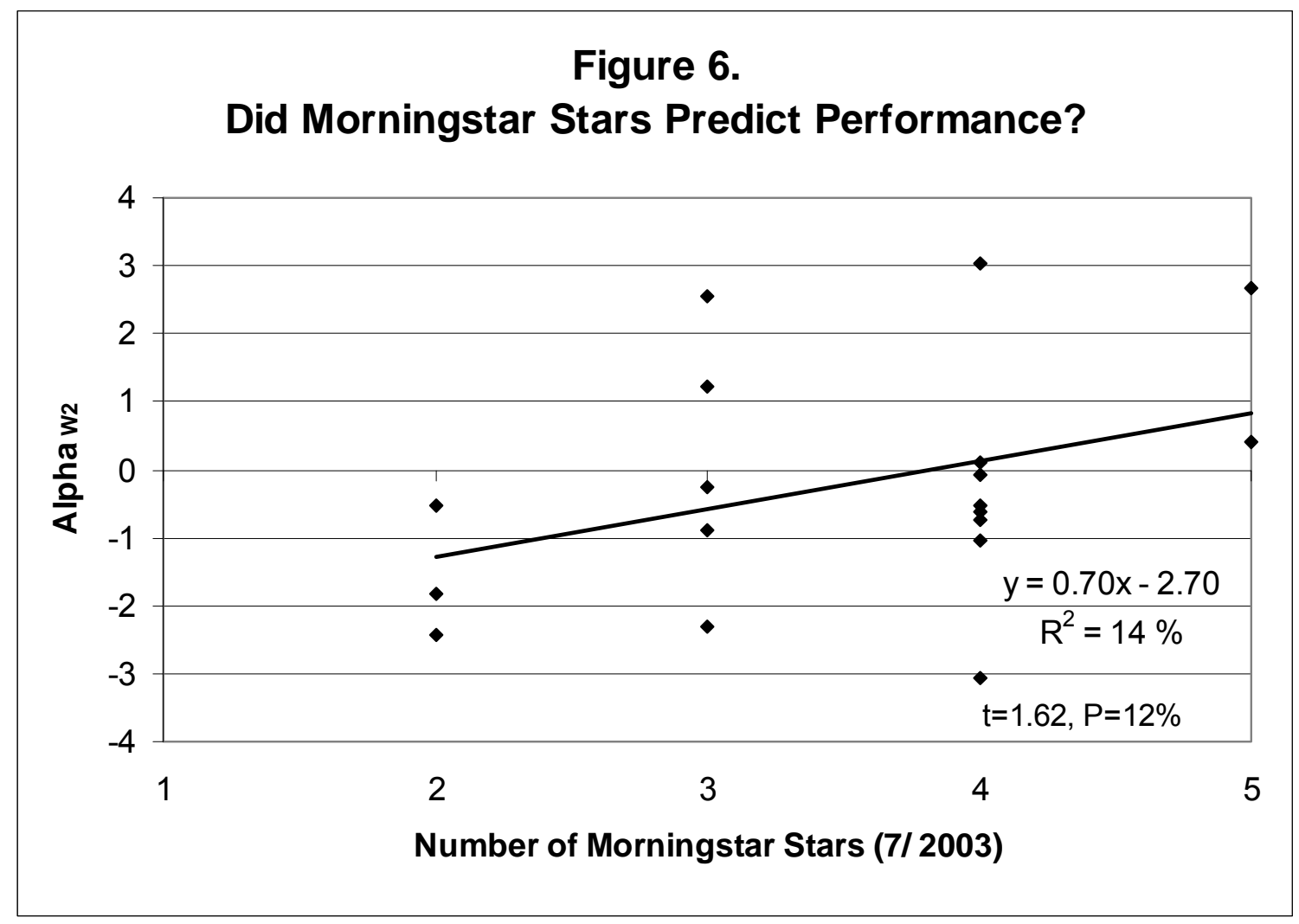




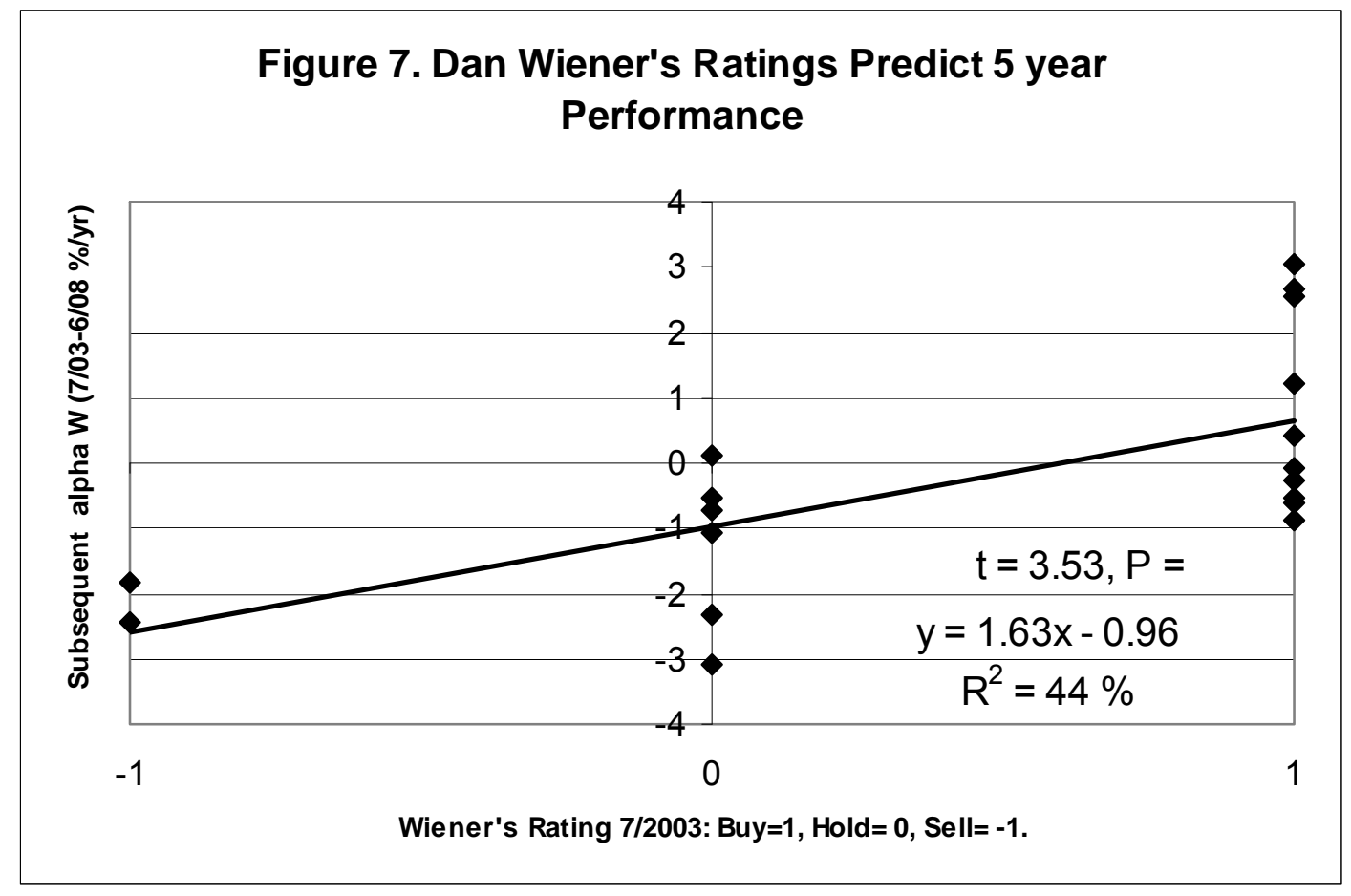




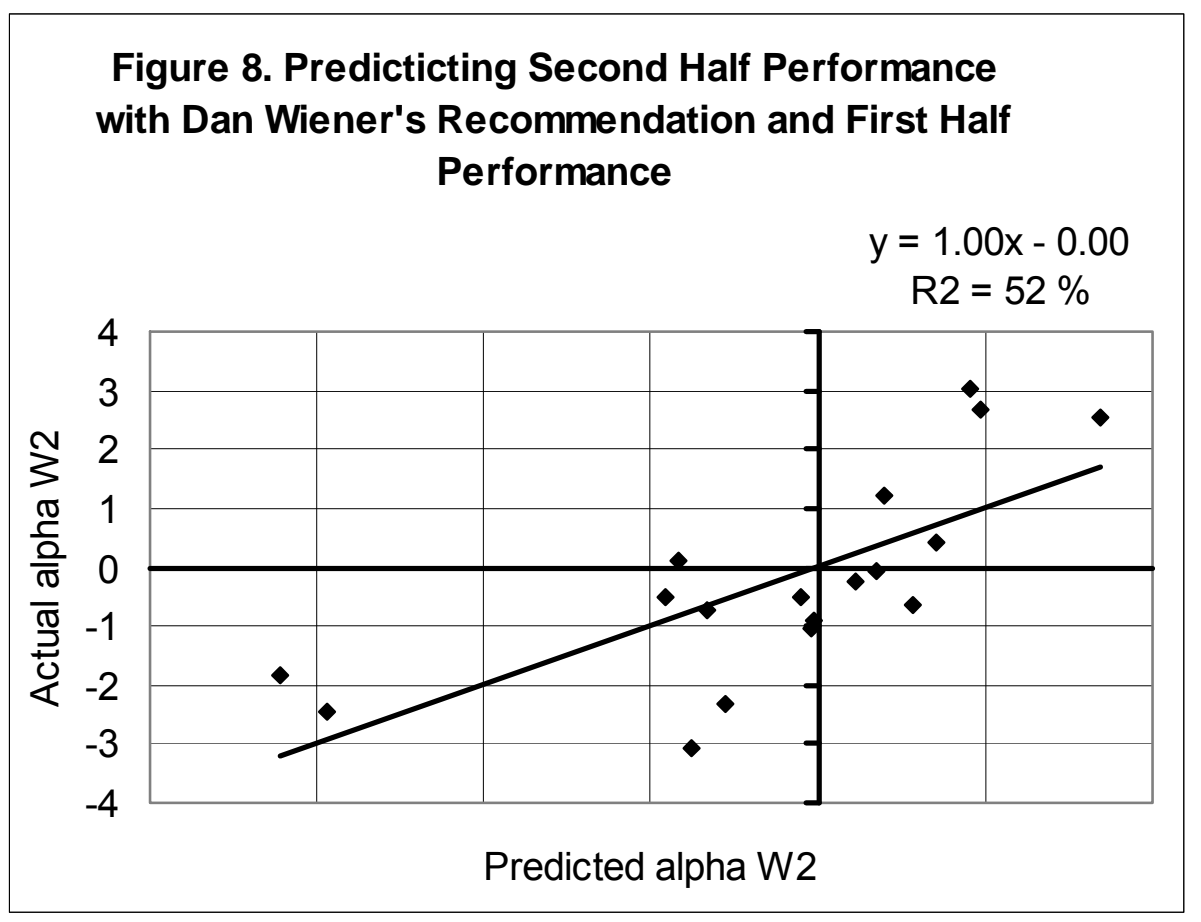

